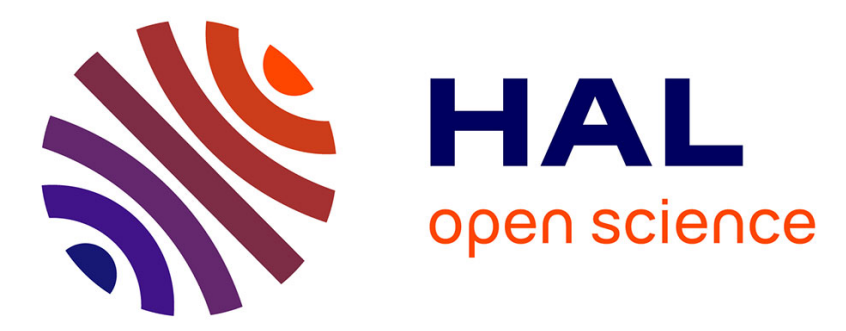

\title{
Antiapoptotic effect of interleukin-2 (IL-2) in B-CLL cells with low and high affinity IL-2 receptors
}

Thomas Decker, Christian Bogner, Madlen Oelsner, Christian Peschel, Ingo Ringshausen

\section{- To cite this version:}

Thomas Decker, Christian Bogner, Madlen Oelsner, Christian Peschel, Ingo Ringshausen. Antiapoptotic effect of interleukin-2 (IL-2) in B-CLL cells with low and high affinity IL-2 receptors. Annals of Hematology, 2010, 89 (11), pp.1125-1132. 10.1007/s00277-010-0994-1 . hal-00545664

\section{HAL Id: hal-00545664 https://hal.science/hal-00545664}

Submitted on 11 Dec 2010

HAL is a multi-disciplinary open access archive for the deposit and dissemination of scientific research documents, whether they are published or not. The documents may come from teaching and research institutions in France or abroad, or from public or private research centers.
L'archive ouverte pluridisciplinaire HAL, est destinée au dépôt et à la diffusion de documents scientifiques de niveau recherche, publiés ou non, émanant des établissements d'enseignement et de recherche français ou étrangers, des laboratoires publics ou privés. 
Editorial Manager(tm) for Annals of Hematology

Manuscript Draft

Manuscript Number: AOHE-D-10-00189R1

Title: Antiapoptotic effect of Interleukin-2 (IL-2) in B-CLL cells with low and high affinity IL-2 receptors

Article Type: Original Article

Keywords: CLL; IL-2; apoptosis; akt

Corresponding Author: Dr Thomas Decker,

Corresponding Author's Institution: Klinikum rechts der Isar

First Author: Thomas Decker

Order of Authors: Thomas Decker; Christian Bogner; Madlen Oelsner; Christian Peschel; Ingo

Ringshausen

Abstract: Although B-CLL cells express the alpha chain of the IL-2 receptor CD25, little is known about the effect of IL-2 on apoptosis in B-CLL cells. We have shown previously that stimulation of B-CLL cells with a CpG-Oligonucleotide induces IL-2 high affinity receptors. In our current work, we analyzed the effect of IL-2 on apoptosis in resting B-CLL cells and in our model of activated B-CLL cells (CD25 high cells).

IL-2 had modest antiapoptotic activity in resting B-CLL cells. In contrast, IL-2 was much more potent to prevent apoptosis in activated cells. Prevention of cell death was also associated with the maintenance of the mitochondrial membrane potential. While only limited regulation of apoptosis controlling proteins was observed in resting B-CLL cells, IL-2 had strong effects on MCL-1, Bcl-xl and survivin expression and inhibited Bax cleavage in CD25 high cells. Interestingly, expression of Bcl-2 was reduced. Addition of IL-2 to activated B-CLL cells caused rapid phosphorylation of Akt while IL-2 failed to significantly phosphorylate Akt in resting B-CLL cells. Pharmcological inhibition of Akt by LY294002 restored sensitivity of activated B-CLL cells to Fludarabine.

IL-2 might be an important survival factor in activated B-CLL cells and contributes to disease progression by up-regulation of several critical antiapoptotic proteins.

Response to Reviewers: Dear Reviewer, Thank you very much for your time and your efforts.

We now provide a substantially shortened version of our manuscript (reduction from 3048 to 2475 words)and Figure 2 was deleted as requested. In addition, the number of citations was reduced from 49 to 41 .

We agree, that substantial shortening improved our manuscript.

Thank you very much again. 


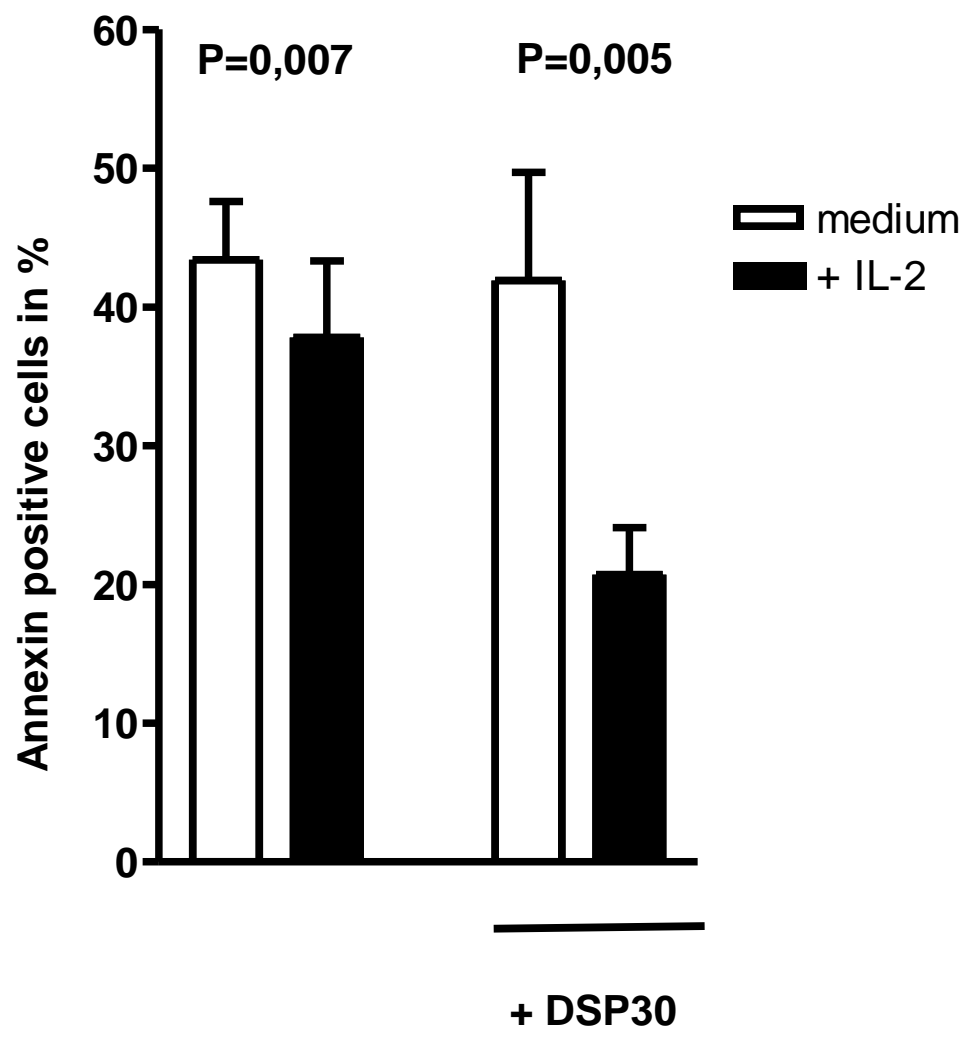

Figure 1: IL-2 reduces cell death in B-CLL cells

Annexin/PI stains were performed after 48 hours of culture of B-CLL cells treated with IL-2 $100 \mathrm{U} / \mathrm{ml}$, DSP30 $1 \mu \mathrm{M}$ or both. The mean percentage of Annexin $\mathrm{V}$ positive cells + SEM of 12 patients is shown 


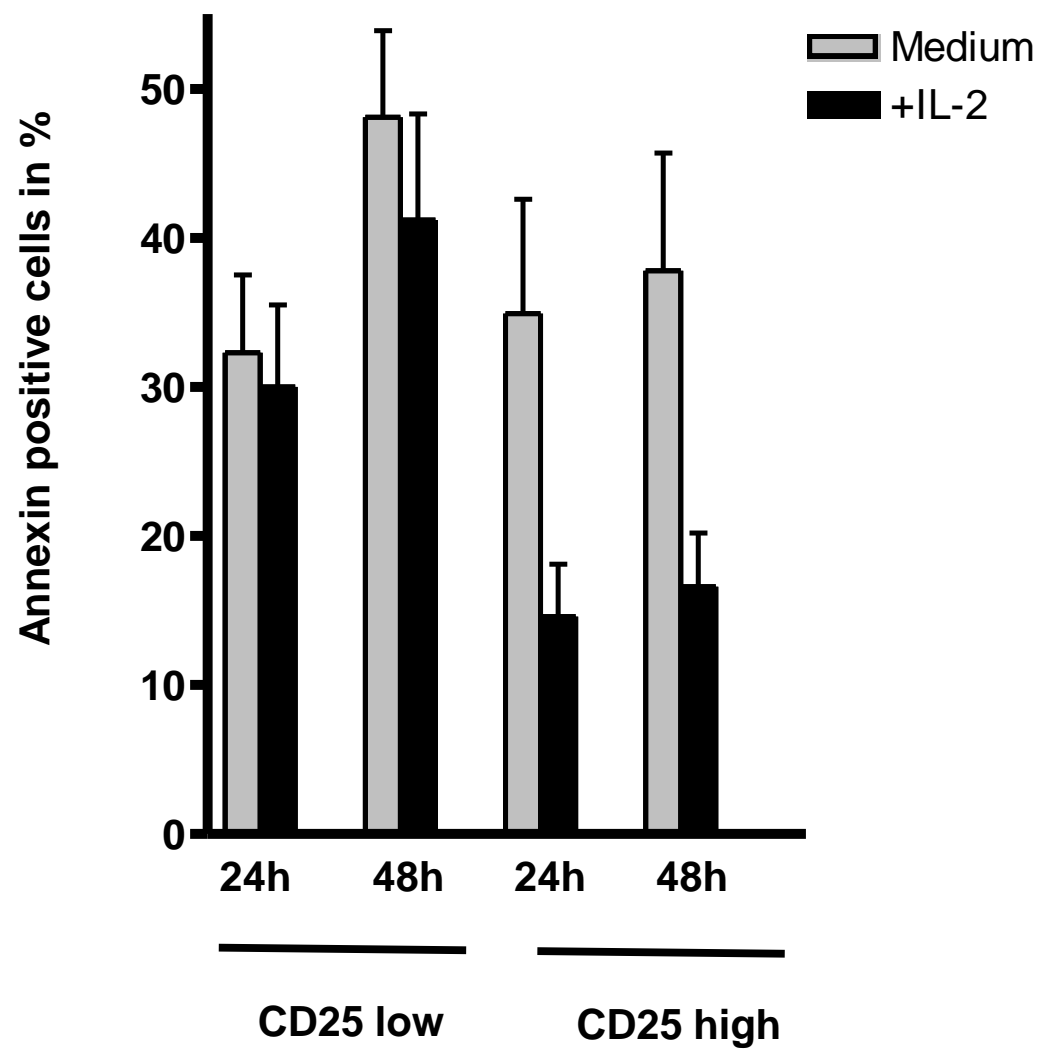

Figure 2: IL-2 effect on viability of CD25 low and CD25 high B-CLL cells.

Annexin/PI staining was performed in 7 independent samples after culture for the indicated times with medium or IL-2 at $100 \mathrm{U} / \mathrm{ml}$. Cells were either cultured immediately after isolation (CD25 low) or after prestimulation with DSP30 and IL-2 for 24hours, followed by an overnight incubation with medium alone (CD25 high). 
CD25 low

A
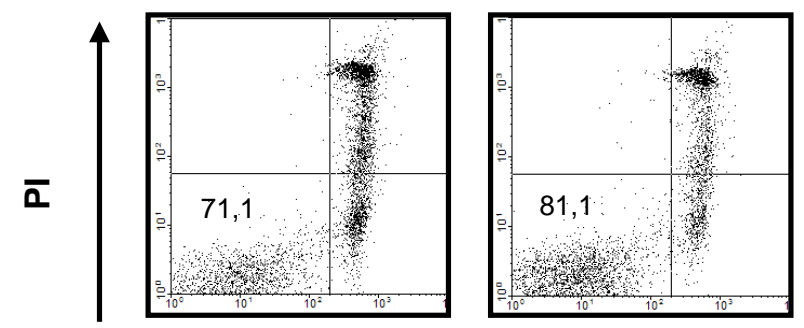

CD25 high

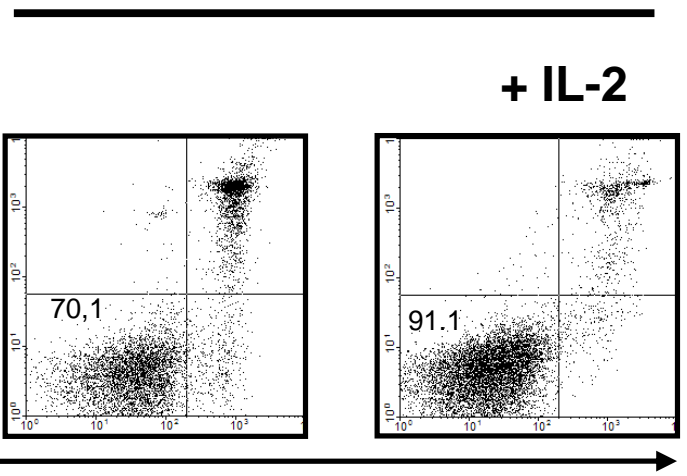

Annexin-V

B
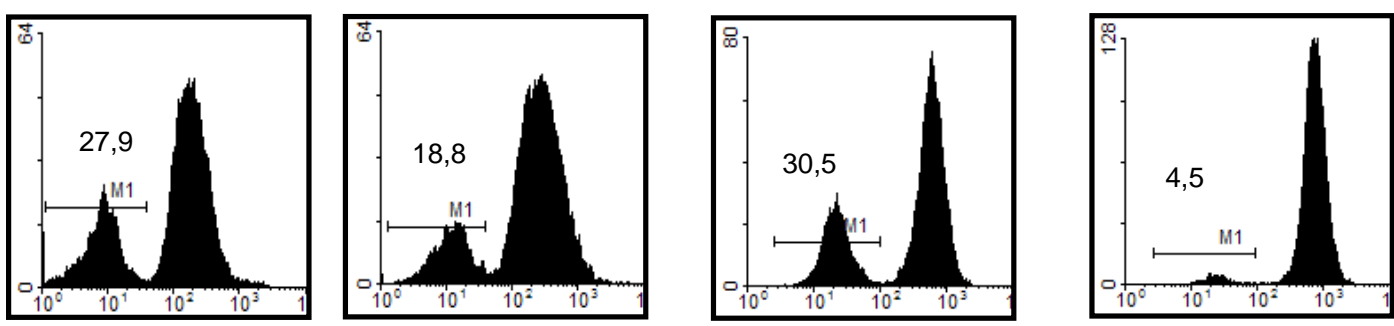

DIOC6(3)
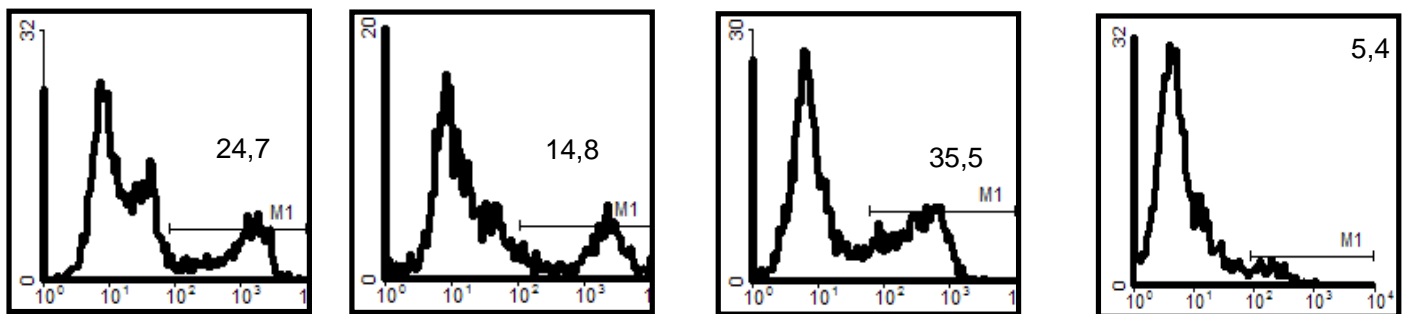

Tunel

Figure 3: Analysis of Phosphatidyl-serine exposure (A), mitochondrial membrane potential (B) and DNA strand brakes (C) in CD25 low or CD25 high cells

Resting or prestimulated B-CLL cells were cultured for 48 hours with or without IL-2. Annexin/PI-statining (A), staining with DIOC6(3) (B) and Tunel staining (C) were performed. One representative experiment is shown, Two additional experiments gave similar results. 
PARP

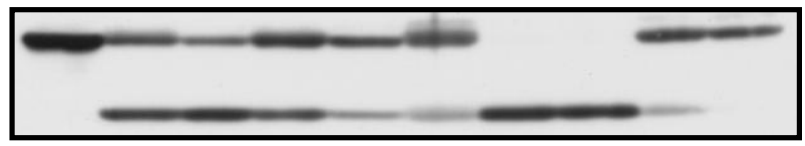

Bcl-xl

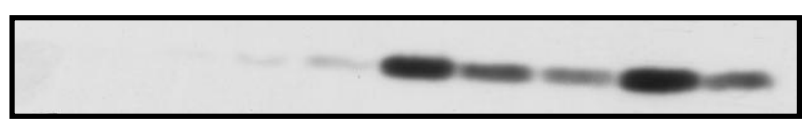

Mcl-1

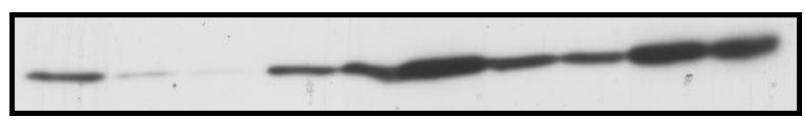

Bcl-2

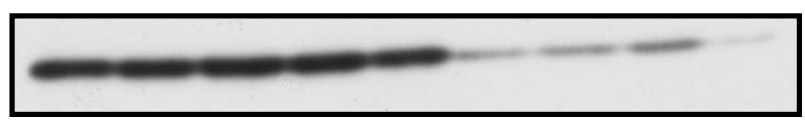

Bax

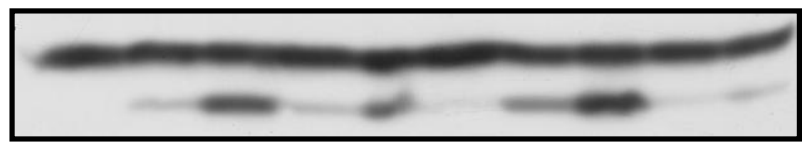

Bak

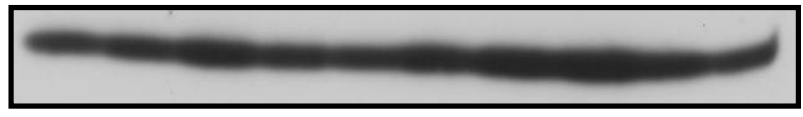

Survivin

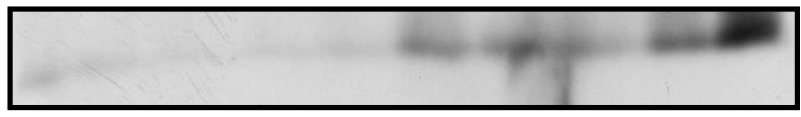

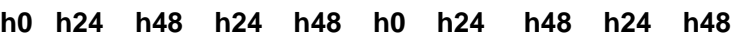

IL-2:

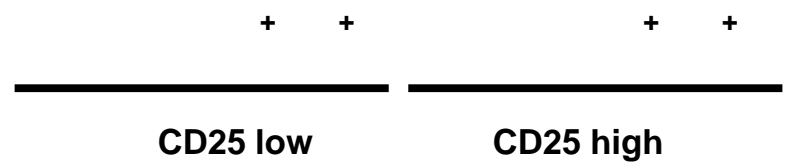

Figure 4: IL-2 effect on expression of critical apoptosis regulating molecules in resting and stimulated $B-C L L$ cells Expression of apoptosis regulating proteins was analysed by western blotting of total cellular lysates after the indicated time of in vitro culture with or without IL-2 at $100 \mathrm{U} / \mathrm{ml}$. 


\section{A: CD25 low}

Phospho-Akt

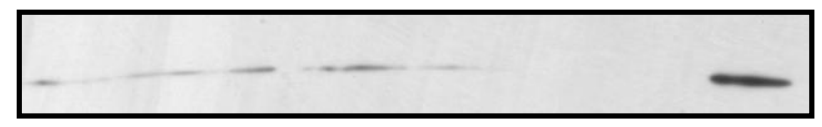

Akt

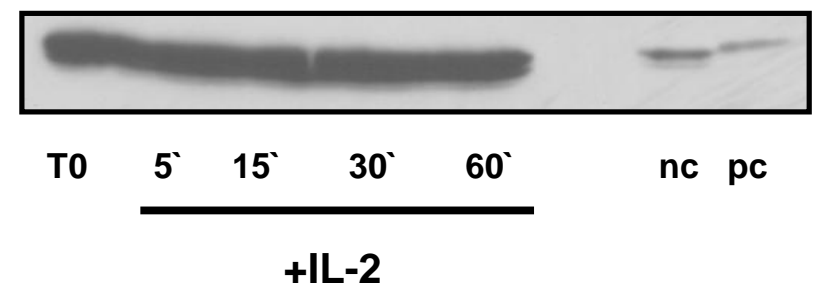

\section{B: CD25 high}

Phospho-Akt

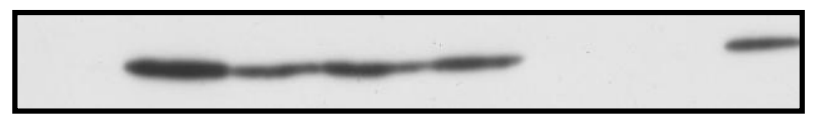

Akt

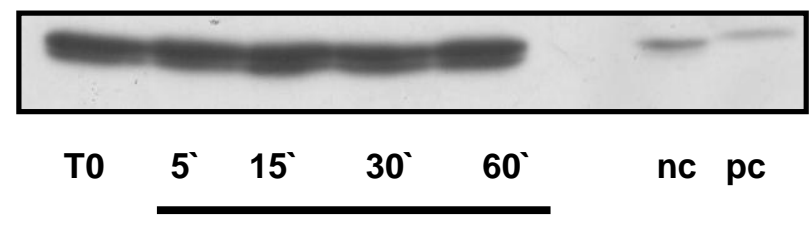

+IL-2

Figure 5: Akt is rapidly phosphorylated in CD25 high B-CLL cells upon addition of IL-2

B-CLL cells were either incubated with IL-2 immediately after purification (A) or after prestimulation with DSP30 and IL-2 as described (B). Cells were then cultured in the presence of IL-2 for the indicated time. Western Blots were performed with antibodies specific for total akt and phosphorylated akt (Ser473). Pc means positive control, nc negative control 


\section{Phospho-Akt}

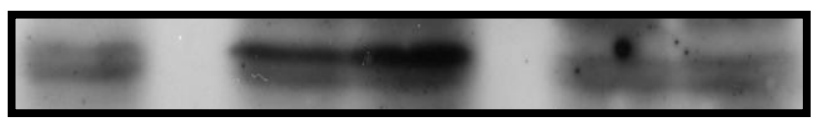

Akt

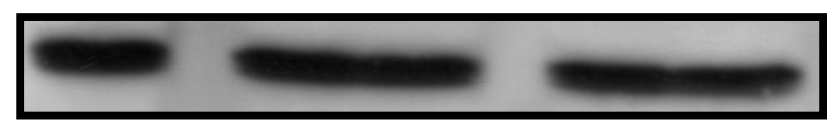

T0 $30^{\circ} 60^{\circ} \quad 30^{\circ} 60^{`}$

+ IL-2

+ Ly

Figure 6: Akt phosphorylaton by IL-2 is inhibited by LY294002 (Ly)

After prestimulation with DSP30 and IL-2 for 24 hours, followed by an overnight incubation in medium alone, cells were stimulated with IL2 with or without LY294002 $(10 \mu \mathrm{M})$ for the indicated time. Western Blots were performed with antibodies specific for total akt and phosphorylated akt (Ser473). Two additional experiments gave similar results. 
A

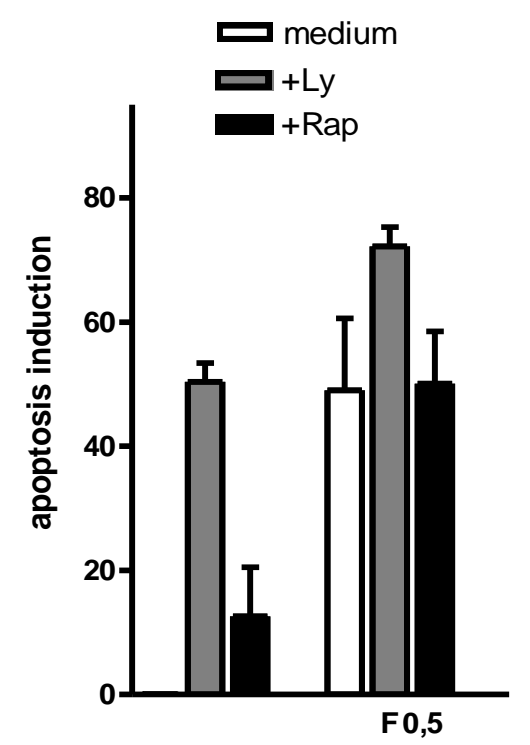

B

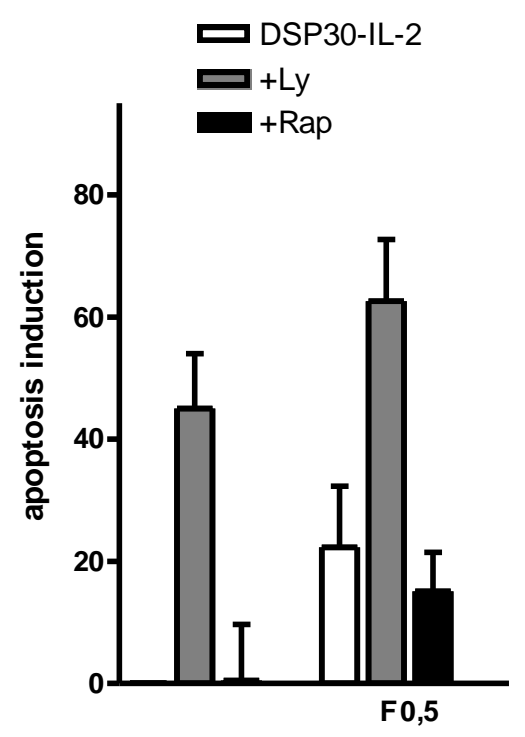

Figure 7: Pharmacological inhibition of the AKt pathway restores senstitivity to Fludarabin in CD25 high B-CLL cells.

B-CLL cells were cultured for 48 hours in medium alone or in the presence of DSP30 and IL-2 with or without Ly294002 $(10 \mu \mathrm{M})$ or Rapamycin $(50 \mathrm{ng} / \mathrm{ml})$. Fludarabin (F) was added at $500 \mathrm{ng} / \mathrm{ml}$ as indicated. Apoptosis induction was calculated as described. Mean +/- SEM of 5 individual experiments are shown. 


\section{Antiapoptotic effect of Interleukin-2 (IL-2) in B-CLL cells with low and high affinity}

\section{IL-2 receptors}

Thomas Decker ${ }^{1,2}$, Christian Bogner ${ }^{1}$, Madlen Oelsner ${ }^{1}$, Christian Peschel ${ }^{1}$ and Ingo Ringshausen $^{1}$

${ }^{1}$ From the Illrd Department of Medicine, Technical University of Munich, Munich, Germany and ${ }^{2}$ Onkologie Ravensburg, Ravensburg, Germany

Total word count: 2475

Figures: 7

Correspondence to

Thomas Decker, M.D.

Onkologie Ravensburg

Wilhelm Hauff Str 41

88214 Ravensburg, Germany

Tel.: (-49)-751-3665035 Fax: (-49)-751-3665036

email: t.decker@Irz.tu-muenchen.de

This work was supported by a research grant from the Jose Carreras Leukemia fund R05/17

Running title: IL-2 in B-CLL abstract word count: 204

References: 41 
Abstract:

Although B-CLL cells express the alpha chain of the IL-2 receptor CD25, little is known about the effect of IL-2 on apoptosis in B-CLL cells. We have shown previously that stimulation of B-CLL cells with a CpG-Oligonucleotide induces IL-2 high affinity receptors. In our current work, we analyzed the effect of IL-2 on apoptosis in resting B-CLL cells and in our model of activated B-CLL cells (CD25 high cells).

IL-2 had modest antiapoptotic activity in resting B-CLL cells. In contrast, IL-2 was much more potent to prevent apoptosis in activated cells. Prevention of cell death was also associated with the maintenance of the mitochondrial membrane potential. While only limited regulation of apoptosis controlling proteins was observed in resting B-CLL cells, IL-2 had strong effects on MCL-1, Bcl-xl and survivin expression and inhibited Bax cleavage in CD25 high cells. Interestingly, expression of $\mathrm{Bcl}-2$ was reduced. Addition of IL-2 to activated B-CLL cells caused rapid phosphorylation of Akt while IL-2 failed to significantly phosphorylate Akt in resting B-CLL cells. Pharmcological inhibition of Akt by LY294002 restored sensitivity of activated B-CLL cells to Fludarabine.

IL-2 might be an important survival factor in activated B-CLL cells and contributes to disease progression by up-regulation of several critical antiapoptotic proteins. Keywords: CLL; IL-2; apoptosis; akt 


\section{Introduction:}

B chronic lymphocytic leukemias (B-CLL) have been defined as the accumulation of slow-dividing and long lived B lymphocytes closely resembling small resting B lymphocytes [1]. However, recent research has demonstrated that B-CLL is rather characterized by a dynamic interplay between birth and death $[2,3]$.

B-CLL cells seem to rely on supportive signals from the microenvironment, where cellular interactions and cytokines can inhibit apoptosis and promote proliferation [4]. A variety of cell types might be important in this supportive environment, where autologous $T$ cells might provide cytokines involved in proliferation and apoptosis inhibition of malignant $B$ cells $[5,6]$.

IL-2 is the prototype cytokine of a cytokine family, which shares the IL-2 gamma chain receptor as a receptor component [7]. Although IL-2 is regarded as a key growth and death factor in antigen activated $T$ cells and regulatory $T$ cells [8], it has important functions in other lineages as well [9].

The reactivity of lymphocytes to II-2 is mediated by multimeric high affinity receptors $(\mathrm{Kd}=10 \mathrm{pM})$ consisting of two obligate signaling subunits, IL-2RB (CD122) and $\gamma$ (CD132), and a variably expressed IL-2Ra (CD25) which regulates affinity for IL-2 [10].

After hetero-dimerization of the receptor complexes, IL-2 transduces its signals via different molecules including the Jak-Stat, the MAP kinase and the PI-3 kinase pathways. These signaling events usually result in cellular proliferation and inhibition of apoptosis [11].

B-CLL cells express CD25 at low levels [12]. We and others have demonstrated that upregulation of CD25 in stimulated B-CLL cells results in the formation of functional high affinity receptors $[13,14]$. Importantly, IL-2 has demonstrated its potency to increase Immunglobulin secretion, cytokine production and upregulation of surface 
molecules in such stimulated cells [15-17] . IL-2 can be provided by autologous T cells, infiltrating lymph nodes or the bone marrow [18].

Importantly, IL-2 has been demonstrated to increase B-CLL proliferation and to promote cell cycle progression in a variety of experimental models [16, 17].

In addition to cellular proliferation, cell accumulation caused by impaired apoptosis is clearly involved in disease progression [2]. However, the role of IL-2 in apoptosis prevention in leukemic B-CLL cells is not well defined .

In the present study, we investigate the potential of IL-2 to inhibit apoptosis in purified resting B-CLL cells and in stimulated leukemic cells expressing high affinity II-2 receptors. Our results point to a potential role of IL-2 in apoptosis inhibition especially in stimulated B-CLL cells. 


\section{Materials and Methods:}

Cell samples: After informed consent, peripheral blood was obtained from patients with a diagnosis of B-CLL according to clinical and immunophenotypic criteria. Patients were either untreated or had not received cytoreductive chemotherapy for a period of at least three months prior to investigation. At the time of analysis all patients were clinically stable, free from infectious complications and undergoing routine clinic out-patient review.

Reagents and antibodies:

The ODN DSP30 (TCGTCGCTGTCTCCGCTTCTTCTTGCC) was used single stranded, phosphorothioate stabilized and synthesised by TibMolBiol (Berlin, Germany). IL-2 was obtained from Pepro Tech (London, UK). DiOC6(3) (3,3' dihexyloxacarbocyanine iodide) was obtained from Molecular Probes (Eugene, Oregon, USA), AnnexinV-FITC Kit was purchased from Immunotech (Marseille, France). Murine mAbs specific for Mcl-1, PARP were obtained from Santa Cruz (Santa Cruz, Ca, USA). MAbs for Bcl-2 and Bax from BD Pharmingen (San Diego, Ca., USA). mAb for B-actin (from Sigma, Deisenhofen, Germany). Bcl-xl was from BD Scientific (San Jose, California, USA); Akt and phospho akt (Ser473) as well as lysates for positive and negative controls were purchased from Cell Signalling (Danvers, MA, USA). Survivin was obtained from R\&D Systems (Minneapolis, MN, USA)

Separation procedures: Peripheral blood mononuclear cells (PBMNC) were isolated from heparinized blood samples by centrifugation over a Biocoll separating solution (Biochrom KG seromed ${ }^{\circledR}$, Berlin, Germany) of $1.077 \mathrm{~g} / \mathrm{ml}$ density. For separation of B-CLL cells, PBMNC were incubated with anti-CD2 and anti-CD14 magnetic beads (Dynabeads M450, Dynal, Oslo, Norway) according to the manufacturer's instructions. Such prepared B cells from CLL patients were $>98 \%$ pure as assessed 
by direct immunofluorescence using a Coulter Epics XL (Coulter, Hamburg, Germany). Culture conditions: Purified leukemic B cells were cultured in RPMI 1640 medium (Gibco, Berlin, Germany) supplemented with 10\% fetal calf serum (Biochrom KG seromed ${ }^{\circledR}$, Berlin, Germany), penicillin/streptomycin 501U/ml, Napyruvate $1 \mathrm{mM}$, L-glutamine $2 \mathrm{mM}$, L-asparagine $20 \mu \mathrm{g} / \mathrm{ml}$, 2-mercaptoethanol 0.05mM, HEPES 10mM and MEM non-essential amino acids 0.7x (Biochrom, Berlin, Germany) at $37^{\circ} \mathrm{C}$ and $5 \% \mathrm{CO} 2$ in a fully humidified atmosphere. 
Flow cytometric analysis: To determine apoptosis associated parameters, purified B

cells were cultured at $1 \times 10^{6}$ cells $/ \mathrm{ml}$ either in medium alone or together with DSP30 $(1 \mu \mathrm{M})$ and $\mathrm{IL}-2(100 \mathrm{U} / \mathrm{ml})$ at the indicated concentrations. The samples were washed with PBS and resuspended in 500 $\mu$ l binding buffer (AnnexinV-FITC Kit, Immunotech, Marseille, France), containing $1 \mu \mathrm{l}$ of AnnexinV-FITC stock and $5 \mu \mathrm{l}$ of $20 \mu \mathrm{g} / \mathrm{ml} \mathrm{PI}$ (propidium iodide) for determination of phosphatidylserine (PS) exposure on the outer plasma membrane. After incubation for 10 minutes at room temperature in a light protected area, the specimens were quantified by flow cytometry, using a Coulter Epics XL cytofluorometer, acquiring 5.000 events. Viable cells were both AnnexinV and PI negative. For evaluation of drug induced apoptosis, apoptosis induction was calculated by subtracting viable cells cultured in medium control from viable cells after incubation with the indicated substance. For these experiments, cells were incubated with LY290042 (Calbiochem, Schwalbach, Germany), Rapamycin or Fludarabine (Sigma, Deisenhofen, Germany) as indicated.

To investigate the mitochondrial membrane potential $\Delta \Psi$, the cells were incubated with 3,3'-dihexyloxacarbocyanine iodide (DiOC6(3), 20nM) for 30 minutes at $37^{\circ}$, washed in PBS, resuspended in $500 \mu \mathrm{l}$ binding buffer (AnnexinV-FITC Kit, Immunotech), containing $5 \mu \mathrm{l}$ of $20 \mu \mathrm{g} / \mathrm{ml} \mathrm{PI}$ and were analyzed via flow cytometry, acquiring 5.000 events.

DNA fragmentation assay: To identify fragmented DNA, a TdT-mediated dUTP nickend labeling (Tunel) assay was performed and assessed by cytometry (Boehringer Mannheim, Indianapolis, IN, USA). $10^{6}$ cells per sample were washed in PBS and fixed in $2 \%$ paraformaldehyde for 30 minutes at room temperature. After fixation, the cells were washed twice in PBS containing $0.01 \%$ BSA and resuspended in TUNEL reaction mixture containing fluorescein dUTP. Fluorescein incorporated in DNA strand breaks was detected by flow cytometry. 
Results:

IL-2 inhibits apoptosis in resting and in stimulated B-CLL cells.

Purified B-CLL cells were cultured with IL-2 100U/ml for 48 hours. Cells were either cultured in medium or together with the immunostimulatory oligonucleotide (ODN) DSP30. Apoptosis induction was modestly but significantly inhibited in resting B-CLL cells. This effect was much stronger in B-CLL cells cultured in the presence of DSP30 (Figure 1). The antiapoptotic effect was also evident with IL-2 at 10U/ml and could not be increased with higher doses (data not shown).

Stimulation with CpG ODN has a diverse effect on apoptosis in B-CLL cells $[19,20]$. In our experimental setting, stimulation with DSP30 resulted in apoptosis induction in 4 of 12 samples while an antiapoptotic effect was observed in the remaining samples (table 1). To be able to analyze the effect of IL-2 in CLL cells in the absence of additional signals mediated by CpG ODN, we cultured B-CLL cells for 24 hours with IL-2 and CpG ODN, followed by overnight incubation in medium alone. These cells expressed the $\alpha$ chain of the IL-2 receptor at high levels (data not shown) and are called "CD25 high" cells in the following experiments. The antiapoptotic effect of IL-2 in these cells was much stronger than in resting B-CLL cells (Figure 2). 


\section{Mechanism of inhibition of apoptosis by IL-2}

The mitochondrial membrane potential $\Delta \Psi$ was nearly completely intact in IL-2 treated CD25 high cells. A smaller effect was observed in CD25 low cells. The intact membrane potential was strongly correlated with a reduction of DNA strand brakes, reduction of phosphatidylserine exposure and inhibition of PARP cleavage (Figure 3, Figure 4).

In CD25 high cells, Bcl-xl expression was increased in the presence of IL-2 and no effect was observed in CD25 low cells. In contrast, MCL-1 was increased upon addition of IL-2 in both CD25 low and high cells. However, expression levels in CD25 high cells were much higher. Expression levels of Bcl-2 did not change in CD25 low cells, but Bcl-2 expression was strongly reduced in CD25 high cells and was no longer detectable if IL-2 was added.

BAX and Bak expression levels were not changed in CD25 low or high cells but Bax cleavage was inhibited in CD25 high cells upon stimulation with IL-2. In addition, survivin expression was strongly increased in IL-2 stimulated CD25 high cells. Results are shown in Figure 4. Two additional experiments gave very similar results.

Akt phosphorylation in response to IL-2 in CD25 low and high cells.

The AKt pathway has been demonstrated to be involved in B-CLL survival [21, 22] and is an important part of the IL-2 signal transduction system [23]. Therefore, we analyzed akt phosphorylation in response to IL-2 in CD25 high and CD25 low cells. Phosphorylation at Serine 473, which is an important phosphorylation site [24], was rapidly observed in CD25 high cells, while only marginal phosphorylation was observed in CD25 low cells upon incubation with IL-2 (Figure 5). 
Akt phosphorylation at Serine 473 was inhibited in the presence of LY294002 (LY), an inhibitor of the PI3 kinase pathway. One representative experiment out of three performed is shown in Figure 6.

Chemotherapy resistance of activated B-CLL cells is reverted by LY294002

Because IL-2 has a strong antiapoptotic effect in activated B-CLL cells, we were interested, whether IL-2 could also confer resistance against chemotherapy in these cells. Therefore, we analyzed apoptosis induction in resting and CD25 high BCLL cells in the presence of fludarabine at $500 \mathrm{ng} / \mathrm{ml}$. While strong apoptosis induction was observed in resting B-CLL cells, fludarabine induced only limited apoptosis in activated B-CLL cells. We have reported previously that LY induces apoptosis in resting B-CLL cells [25] - a similar effect occurred in CD25 high cells. Importantly, apoptosis induction by fludarabine was markedly increased in activated B-CLL cells, while treatment with rapamycin did not change the degree of cell death. The results of five different experiments are shown in Figure 7 (mean +/- SEM).

\section{Discussion}

The present study demonstrates that IL-2 clearly has antiapoptotic properties in BCLL cells. The antiapototic effects of IL-2 are much more pronounced in activated (CD25 high) cells than in resting B-CLL cells, which is in sharp contrast to the role of IL-2 in promoting activation induced cell death in T cells[26].

Involvement of IL-2 in the pathogenesis of B-CLL has been postulated for a long time [27] but previous research has focused on proliferation and expression of costimulatory molecules[15]. IL-2 is mainly produced by activated T cells and is a key cytokine involved in the expansion and development of $T$ cells, especially regulatory T cells [8]. Indeed, the overall pool of T cells is significantly increased in B-CLL cells 
with a high frequency of CD4 T cell expansion [28] and increased numbers of regulatory T cells correlate with disease burden [29].

In B-CLL patients, CD3 positive T cells can be detected in clusters with survivin expressing and proliferating B-CLL cells in lymph nodes [30, 31]. In addition, autologous T cells have been shown to inhibit apoptosis in cocultured B-CLL cells [4, 17] and we have previously demonstrated that IL-2 production by activated T cells is increased when B-CLL cells are added to autologous $T$ cells [32]. Therefore, IL-2 might well be an important factor in the microenvironment of B-CLL cells which is thought to be important for disease progression [33].

In our present study, we observed a small but significant anti-apoptotic effect of IL-2 in resting B-CLL cells. More important, IL-2 had strong anti-apoptotic properties in our model of activated B-CLL cells (Figure 2).

In CD25 low cells, IL-2 prevented MCL-1 downregulation with no effect on bcl-2 expression (Figure 5). Both proteins of the bcl-2 family have been described to be important for B-CLL pathophysiology [34, 35]. MCL-1 downregulation was also prevented in CD25 high cells, but bcl-2 levels declined. Reduced bcl-2 expression has been described in activated B-CLL cells previously [36] and might be a consequence of a higher percentage of B-CLL cells in S-phase of the cell cycle in our "CD25 high cells" $[16,37]$. In contrast, expression of the antiapoptotic proteins bcl-xl and survivin were strongly enhanced in the presence of IL-2 in CD25 high cells. Therefore, the expression of antiapoptotic proteins in CD25 high cells treated with IL2 strongly resembles the high bcl-xl, survivin and MCL-1 expression in B-CLL cells in lymph nodes with proliferation centers [30, 38, 39].

Importantly, T cells in the microenvironment may induce CD25 upregulation in B-CLL cells by providing CD40 ligand and IL-10 as well as IL-2 [14, 32]. IL-2 is then able to both induce proliferation and prevent apoptosis in the malignant cells and might 
therefore play a central role in the balance between proliferation and apoptosis, which is determined in lymphoid tissues [40].

The serine threonine kinase Akt is a major effector of the PI3Kinase pathway in cancer and a central regulator of cell growth, survival and chemotherapy resistance. [41]. Akt activation is thought to be involved in B-CLL progression and has been shown to mediate resistance against chemotherapy and radiation [22].

While no Akt activation was observed in CD25 low cells, Akt was rapidly phosphorylated in CD 25 high cells. In addition, pharmacological inhibition of Akt activation was able restore sensitivity to Fludarabine in IL-2 treated CD25 high cells (Figures 5-7).

Taken together, IL-2 might contribute to disease progression in B-CLL by inhibiting apoptosis especially in activated leukemic cells via Akt phosphorylation and upregulation of the antiapototic proteins MCL-1, BCL-xl and survivin.

In addition, IL-2 might protect these cells against the effects of cytotoxic chemotherapy. Therefore, IL-2 might be an important part of a microenvironment, suitable for expansion and survival of the malignant clone.

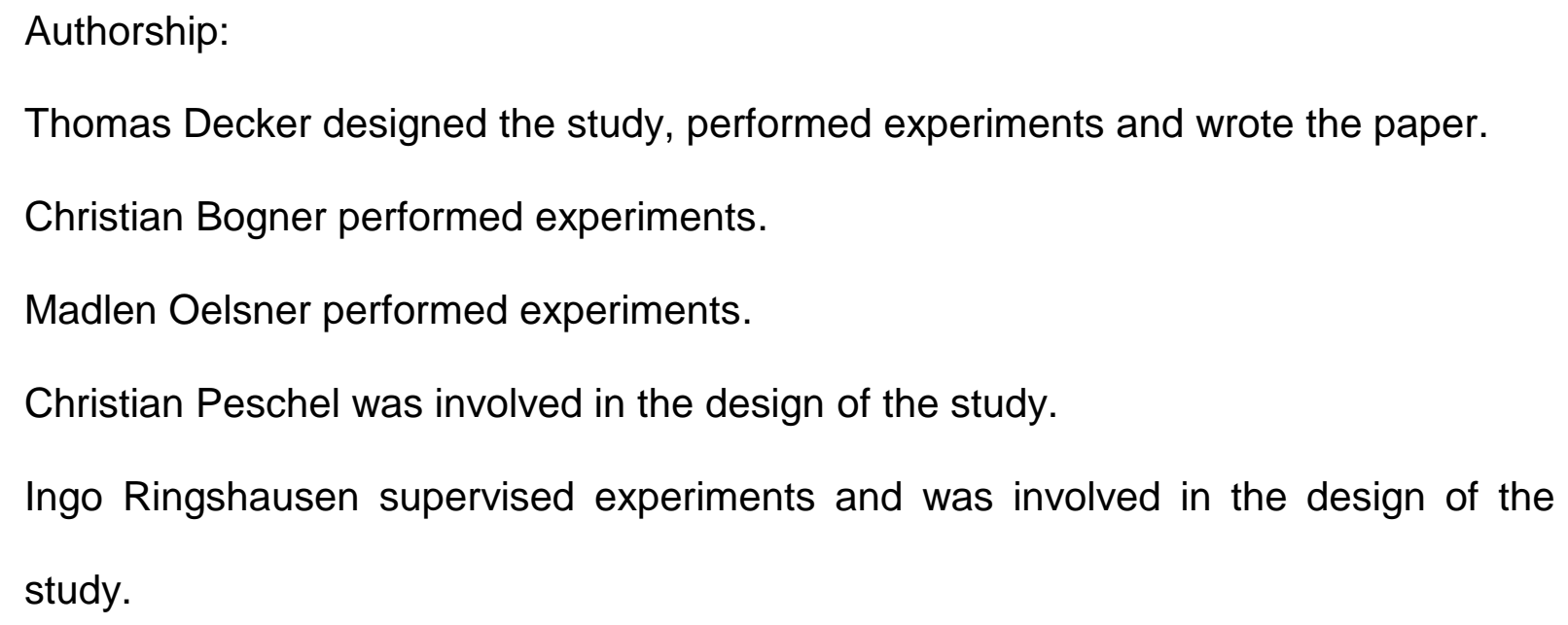




\section{Table 1:}

Annexin positive cells after 48 hours incubation in medium, IL-2, DSP30 or the combination of both

\begin{tabular}{|c|c|c|c|c|c|}
\hline Pt nr & Med & IL-2 & DSP30 & DSP30 + IL-2 & ZAP70 \\
\hline$\# 1$ & 64,9 & 60,4 & 70,1 & 37,4 & pos. \\
\hline$\# 2$ & 63,9 & 63,7 & 16.0 & 10,4 & pos \\
\hline$\# 3$ & 52.3 & 50.3 & 37,2 & 37,3 & pos \\
\hline$\# 4$ & 33,1 & 14,7 & 75,7 & 16,5 & neg \\
\hline$\# 5$ & 49, & 50, & 43,7 & 32,2 & pos \\
\hline$\# 6$ & 59,4 & 60,5 & 17,0 & 13,2 & n.d. \\
\hline$\# 7$ & 34,0 & 27,7 & 80,4 & 29,9 & neg \\
\hline$\# 8$ & 29,3 & 26,6 & 5,8 & 6,2 & n.d. \\
\hline$\# 9$ & 41,3 & 35,8 & 76,1 & 26,5 & pos \\
\hline$\# 10$ & 17,5 & 4,6 & 15,3 & 3,7 & neg \\
\hline$\# 11$ & 37,0 & 30,8 & 32,8 & 21,0 & pos \\
\hline$\# 12$ & 39,6 & 28,0 & 33,3 & 15,1 & pos \\
\hline
\end{tabular}


1. O'Brien, S., del Giglio, A., Keating, M. (1995) Advances in the biology and treatment of B-cell chronic lymphocytic leukemia. Blood 85, 307-18.

2. Chiorazzi, N. (2007) Cell proliferation and death: forgotten features of chronic lymphocytic leukemia B cells. Best Pract Res Clin Haematol 20, 399-413.

3. Messmer, B.T., Messmer, D., Allen, S.L., Kolitz, J.E., Kudalkar, P., Cesar, D., Murphy, E.J., Koduru, P., Ferrarini, M., Zupo, S., Cutrona, G., Damle, R.N., Wasil, T., Rai, K.R., Hellerstein, M.K., Chiorazzi, N. (2005) In vivo measurements document the dynamic cellular kinetics of chronic lymphocytic leukemia B cells. J Clin Invest 115, 755-64.

4. Ghia, P., Circosta, P., Scielzo, C., Vallario, A., Camporeale, A., Granziero, L., Caligaris-Cappio, F. (2005) Differential effects on CLL cell survival exerted by different microenvironmental elements. Curr Top Microbiol Immunol 294, 135-45.

5. Caligaris-Cappio, F., Hamblin, T.J. (1999) B-cell chronic lymphocytic leukemia: a bird of a different feather. J Clin Oncol 17, 399-408.

6. Patten, P.E., Buggins, A.G., Richards, J., Wotherspoon, A., Salisbury, J., Mufti, G.J., Hamblin, T.J., Devereux, S. (2008) CD38 expression in chronic lymphocytic leukemia is regulated by the tumor microenvironment. Blood.

7. Giri, J.G., Ahdieh, M., Eisenman, J., Shanebeck, K., Grabstein, K., Kumaki, S., Namen, A., Park, L.S., Cosman, D., Anderson, D. (1994) Utilization of the beta and gamma chains of the IL-2 receptor by the novel cytokine IL-15. Embo J 13, 2822-30.

8. Malek, T.R. (2007) The Biology of Interleukin-2. Annu Rev Immunol.

9. Parrish-Novak, J., Dillon, S.R., Nelson, A., Hammond, A., Sprecher, C., Gross, J.A., Johnston, J., Madden, K., Xu, W., West, J., Schrader, S., Burkhead, S., Heipel, M., Brandt, C., Kuijper, J.L., Kramer, J., Conklin, D., Presnell, S.R., Berry, J., Shiota, F., Bort, S., Hambly, K., Mudri, S., Clegg, C., Moore, M., Grant, F.J., Lofton-Day, C., Gilbert, T., Rayond, F., Ching, A., Yao, L., Smith, D., Webster, P., Whitmore, T., Maurer, M., Kaushansky, K., Holly, R.D., Foster, D. (2000) Interleukin 21 and its receptor are involved in NK cell expansion and regulation of lymphocyte function. Nature 408, 57-63.

10. Nelson, B.H., Willerford, D.M. (1998) Biology of the interleukin-2 receptor. Adv Immunol 70, 1-81.

11. Lin, J.X., Leonard, W.J. (2000) The role of Stat5a and Stat5b in signaling by IL-2 family cytokines. Oncogene 19, 2566-76.

12. Damle, R.N., Ghiotto, F., Valetto, A., Albesiano, E., Fais, F., Yan, X.J., Sison, C.P., Allen, S.L., Kolitz, J., Schulman, P., Vinciguerra, V.P., Budde, P., Frey, J., Rai, K.R., Ferrarini, M., Chiorazzi, N. (2002) B-cell chronic lymphocytic leukemia cells express a surface membrane phenotype of activated, antigenexperienced B lymphocytes. Blood 99, 4087-93.

13. Decker, T., Schneller, F., Kronschnabl, M., Dechow, T., Lipford, G.B., Wagner, H., Peschel, C. (2000) Immunostimulatory $\mathrm{CpG}$-oligonucleotides induce functional high affinity IL-2 receptors on B-CLL cells: costimulation with IL-2 results in a highly immunogenic phenotype. Exp Hematol 28, 558-68.

14. Fluckiger, A.C., Garrone, P., Durand, I., Galizzi, J.P., Banchereau, J. (1993) Interleukin 10 (IL-10) upregulates functional high affinity IL-2 receptors on normal and leukemic B lymphocytes. $J$ Exp Med 178, $1473-81$.

15. Tomic, J., White, D., Shi, Y., Mena, J., Hammond, C., He, L., Miller, R.L., Spaner, D.E. (2006) Sensitization of IL-2 signaling through TLR-7 enhances B lymphoma cell immunogenicity. J Immunol 176, 3830-9.

16. Decker, T., Schneller, F., Hipp, S., Miething, C., Jahn, T., Duyster, J., Peschel, C. (2002) Cell cycle progression of chronic lymphocytic leukemia cells is controlled by cyclin D2, cyclin D3, cyclindependent kinase (cdk) 4 and the cdk inhibitor p27. Leukemia 16, 327-34.

17. Tretter, T., Schuler, M., Schneller, F., Brass, U., Esswein, M., Aman, M.J., Huber, C., Peschel, C. (1998) Direct cellular interaction with activated CD4(+) T cells overcomes hyporesponsiveness of Bcell chronic lymphocytic leukemia in vitro. Cell Immunol 189, 41-50.

18. Mellstedt, H., Choudhury, A. (2006) T and B cells in B-chronic lymphocytic leukaemia: Faust, Mephistopheles and the pact with the Devil. Cancer Immunol Immunother 55, 210-20.

19. Jahrsdorfer, B., Jox, R., Muhlenhoff, L., Tschoep, K., Krug, A., Rothenfusser, S., Meinhardt, G., Emmerich, B., Endres, S., Hartmann, G. (2002) Modulation of malignant B cell activation and apoptosis by bcl-2 antisense ODN and immunostimulatory CpG ODN. J Leukoc Biol 72, 83-92.

20. Jahrsdorfer, B., Muhlenhoff, L., Blackwell, S.E., Wagner, M., Poeck, H., Hartmann, E., Jox, R., Giese, T., Emmerich, B., Endres, S., Weiner, G.J., Hartmann, G. (2005) B-cell lymphomas differ in their responsiveness to CpG oligodeoxynucleotides. Clin Cancer Res 11, 1490-9.

21. Longo, P.G., Laurenti, L., Gobessi, S., Petlickovski, A., Pelosi, M., Chiusolo, P., Sica, S., Leone, G., Efremov, D.G. (2007) The Akt signaling pathway determines the different proliferative capacity of 
chronic lymphocytic leukemia B-cells from patients with progressive and stable disease. Leukemia 21, 110-20.

22. Jones, D.T., Ganeshaguru, K., Anderson, R.J., Jackson, T.R., Bruckdorfer, K.R., Low, S.Y., Palmqvist, L., Prentice, H.G., Hoffbrand, A.V., Mehta, A.B., Wickremasinghe, R.G. (2003) Albumin activates the AKT signaling pathway and protects B-chronic lymphocytic leukemia cells from chlorambucil- and radiation-induced apoptosis. Blood 101, 3174-80.

23. Lockyer, H.M., Tran, E., Nelson, B.H. (2007) STAT5 is essential for Akt/p70S6 kinase activity during IL-2-induced lymphocyte proliferation. J Immunol 179, 5301-8.

24. Bayascas, J.R., Alessi, D.R. (2005) Regulation of Akt/PKB Ser473 phosphorylation. Mol Cell 18, 143 5.

25. Ringshausen, I., Schneller, F., Bogner, C., Hipp, S., Duyster, J., Peschel, C., Decker, T. (2002) Constitutively activated phosphatidylinositol-3 kinase (PI-3K) is involved in the defect of apoptosis in B-CLL: association with protein kinase Cdelta. Blood 100, 3741-8.

26. Nelson, B.H. (2004) IL-2, regulatory T cells, and tolerance. J Immunol 172, 3983-8.

27. Karray, S., DeFrance, T., Merle-Beral, H., Banchereau, J., Debre, P., Galanaud, P. (1988) Interleukin 4 counteracts the interleukin 2-induced proliferation of monoclonal B cells. J Exp Med 168, 85-94.

28. Rezvany, M.R., Jeddi-Tehrani, M., Wigzell, H., Osterborg, A., Mellstedt, H. (2003) Leukemiaassociated monoclonal and oligoclonal TCR-BV use in patients with B-cell chronic lymphocytic leukemia. Blood 101, 1063-70.

29. Beyer, M., Kochanek, M., Darabi, K., Popov, A., Jensen, M., Endl, E., Knolle, P.A., Thomas, R.K., von Bergwelt-Baildon, M., Debey, S., Hallek, M., Schultze, J.L. (2005) Reduced frequencies and suppressive function of CD4+CD25hi regulatory $\mathrm{T}$ cells in patients with chronic lymphocytic leukemia after therapy with fludarabine. Blood 106, 2018-25.

30. Granziero, L., Ghia, P., Circosta, P., Gottardi, D., Strola, G., Geuna, M., Montagna, L., Piccoli, P., Chilosi, M., Caligaris-Cappio, F. (2001) Survivin is expressed on CD40 stimulation and interfaces proliferation and apoptosis in B-cell chronic lymphocytic leukemia. Blood 97, 2777-83.

31. Ghia, P., Strola, G., Granziero, L., Geuna, M., Guida, G., Sallusto, F., Ruffing, N., Montagna, L., Piccoli, P., Chilosi, M., Caligaris-Cappio, F. (2002) Chronic lymphocytic leukemia B cells are endowed with the capacity to attract CD4+, CD40L+ T cells by producing CCL22. Eur J Immunol 32, 1403-13.

32. Decker, T., Flohr, T., Trautmann, P., Aman, M.J., Holter, W., Majdic, O., Huber, C., Peschel, C. (1995) Role of accessory cells in cytokine production by T cells in chronic B-cell lymphocytic leukemia. Blood 86, 1115-23.

33. Caligaris-Cappio, F., Ghia, P. (2008) Novel insights in chronic lymphocytic leukemia: are we getting closer to understanding the pathogenesis of the disease? J Clin Oncol 26, 4497-503.

34. Pepper, C., Lin, T.T., Pratt, G., Hewamana, S., Brennan, P., Hiller, L., Hills, R., Ward, R., Starczynski, J., Austen, B., Hooper, L., Stankovic, T., Fegan, C. (2008) Mcl-1 expression has in vitro and in vivo significance in chronic lymphocytic leukemia and is associated with other poor prognostic markers. Blood 112, 3807-17.

35. Cimmino, A., Calin, G.A., Fabbri, M., Iorio, M.V., Ferracin, M., Shimizu, M., Wojcik, S.E., Aqeilan, R.I., Zupo, S., Dono, M., Rassenti, L., Alder, H., Volinia, S., Liu, C.G., Kipps, T.J., Negrini, M., Croce, C.M. (2005) miR-15 and miR-16 induce apoptosis by targeting BCL2. Proc Natl Acad Sci U S A 102, 13944-9.

36. Willimott, S., Baou, M., Naresh, K., Wagner, S.D. (2007) CD154 induces a switch in pro-survival Bcl-2 family members in chronic lymphocytic leukaemia. Br J Haematol 138, 721-32.

37. Zinkel, S., Gross, A., Yang, E. (2006) BCL2 family in DNA damage and cell cycle control. Cell Death Differ 13, 1351-9.

38. Smit, L.A., Hallaert, D.Y., Spijker, R., de Goeij, B., Jaspers, A., Kater, A.P., van Oers, M.H., van Noesel, C.J., Eldering, E. (2007) Differential Noxa/Mcl-1 balance in peripheral versus lymph node chronic lymphocytic leukemia cells correlates with survival capacity. Blood 109, 1660-8.

39. Hallaert, D.Y., Jaspers, A., van Noesel, C.J., van Oers, M.H., Kater, A.P., Eldering, E. (2008) c-Abl kinase inhibitors overcome CD40-mediated drug resistance in CLL: implications for therapeutic targeting of chemoresistant niches. Blood 112, 5141-9.

40. Deaglio, S., Malavasi, F. (2009) Chronic lymphocytic leukemia microenvironment: shifting the balance from apoptosis to proliferation. Haematologica 94, 752-6.

41. Engelman, J.A. (2009) Targeting PI3K signalling in cancer: opportunities, challenges and limitations. Nat Rev Cancer 9, 550-62. 